\title{
Mixture optimization of cement treated demolition waste with recycled masonry and concrete
}

\author{
D. X. Xuan • L. J. M. Houben • \\ A. A. A. Molenaar $\cdot$ Z. H. Shui
}

Received: 3 February 2011 / Accepted: 17 May 2011/Published online: 15 June 2011

(C) The Author(s) 2011. This article is published with open access at Springerlink.com

\begin{abstract}
Due to environmental reasons and the shortage of natural resources, it is greatly valuable to recycle construction and demolition waste (CDW) as much as possible. One of effective ways to reuse more CDW is to produce a cemented road base material. The recycled CDW however is a mix of recycled masonry and concrete with a wide variation in composition. This implies that the mechanical properties of cement treated demolition waste are not only determined by cement content and degree of compaction, but also by the ratio of crushed masonry content to crushed concrete content. In order to optimize its mixture proportioning, this paper explores the response surface and contour plot of the combined effect of mixture variables on the mechanical properties including the unconfined
\end{abstract}

D. X. Xuan $(\varangle)$ L. J. M. Houben · A. A. A. Molenaar Faculty of Civil Engineering and Geosciences, Delft University of Technology, Stevinweg 1, 2628 CN Delft, The Netherlands

e-mail: D.Xuan@tudelft.nl

L. J. M. Houben

e-mail: L.J.M.Houben@tudelft.nl

A. A. A. Molenaar

e-mail: A.A.A.Molenaar@tudelft.nl

Z. H. Shui

School of Materials Science and Engineering, Wuhan

University of Technology, Luoshi Road No. 122,

Wuhan 430070, People's Republic of China

e-mail: zhshui@whut.edu.cn compressive strength (UCS), the elastic modulus $(E)$ and their ratio. It has been recognized that optimizing the mixture proportioning of cement treated demolition waste should not only consider its material properties, but also needs to take into account its structural behavior as a pavement layer. Analytical results indicate that increasing the degree of compaction is an economic technique to obtain the required strength, but it is not an efficient method to enhance the admissible elastic strain (the ratio of UCS to $E$ ) and to improve the flexural rigidity of the road base layer. Obtaining a desired low flexural rigidity certainly needs adjusting of the masonry content and the cement content.

Keywords Cement treated road base - Demolition waste $\cdot$ Response surface $\cdot$ Mixture variables

\section{Introduction}

Cement treated granular materials $\left(\mathrm{CTGM}_{\mathrm{a}}\right)$ are regarded as a kind of intimate mixture with coarse granulates and a relatively small amount of cement compacted at a proper moisture content [1]. They have been widely used as a semi-rigid base course for either flexible or rigid pavements. Being one of the structural pavement layers, its mechanical properties are very important for structural designs [2].

Traditionally, the unconfined compressive strength (UCS) is generally considered as the most important 
mixture design index to determine whether or not the material is suited for road bases. Previous researches have indicated that the UCS is related to cement content, degree of compaction, curing time, material type and so on [3, 4]. Some empirical relationships have been proposed to indicate that the UCS increases linearly with the cement content and increases exponentially with the dry density or degree of compaction. In addition, many linear relationships between the tensile strength of $\mathrm{CTGM}_{\mathrm{a}}$ and its UCS have been reported as well $[5,6]$.

Meanwhile, for pavement design purposes, the stress-strain behavior of $\mathrm{CTGM}_{\mathrm{a}}$ used for a cement treated base (CTB) should also be known, especially its elastic modulus. It is an important index used in linear-elastic multi-layer pavement design system. The expression for the flexural rigidity of a pavement layer [7] is:

$D=\frac{E h^{3}}{12\left(1-v^{2}\right)}$

where, $h$ is the thickness of the CTB layer; $E$ represents the elastic modulus of the CTB material and $v$ is its Poisson's ratio.

Tensile stresses in the CTB as a result of a change in volume due to a drop in temperature and shrinkage can be calculated using:

$\sigma_{\text {deformation }}=E \varepsilon_{\text {deformation }}$

where, $\varepsilon_{\text {deformation }}$ is the strain due to the dimensional change of the CTB layer; $\sigma_{\text {deformation }}$ is the induced stress due to the dimensional change.

For a given pavement structure with a CTB layer, the lower the elastic modulus of the CTB material, the lower the tensile stress due to a dimensional change and the lower the tensile stress due to a traffic load will be. As a result, if the (elastic) admissible strain of $\mathrm{CTGM}_{\mathrm{a}}$, defined as the ratio of strength over modulus given by Eq. 3, is higher, it is more desirable for such pavement application. Therefore, the ratio of strength over modulus is considered as an indicator to design the CTB material, which is given by:

$\varepsilon_{\text {admissible }}=\frac{f_{\text {material }}}{E_{\text {material }}}$

where, $f_{\text {material }}$ is the strength of the material; $\varepsilon_{\text {admissible }}$ is the admissible strain of the CTB material.
Previous researches have reported that the relationship between the strength and the elastic modulus is influenced by mixture variables such as cement content, dry density, gradation and so on [8]. In this study, construction and demolition waste (CDW) is investigated as granulates treated by cement. Because the recycled CDW is a mix of recycled masonry aggregates (RMA) and recycled concrete aggregates (RCA), the ratio of RMA to RCA certainly will influence its mechanical properties $[9,10]$. In order to optimize the mixture proportioning of cement treated mix granulates with RMA and RCA $\left(\mathrm{CTM}_{i} \mathrm{G}_{r}\right)$, it is of great importance to explore the relationships between several explanatory variables and their effect on the mechanical properties.

This paper presents the response surface and contour plot of the combined effect of mixture variables on the UCS, the elastic modulus and their ratio of $\mathrm{CTM}_{i} \mathrm{G}_{r}$. Mixture variables include the cement content, the degree of compaction and the RMA content. By exploring those response surfaces and contour plots, the mixture composition of $\mathrm{CTM}_{i} \mathrm{G}_{r}$ can be optimized to obtain the required mechanical properties.

\section{Mixture design}

In this research, four ratios of RMA to RCA content (percentages by mass) (RMA: RCA) were decided to prepare different types of $\mathrm{CTM}_{i} \mathrm{G}_{r}$ mixtures. They are 0\%:100\%, 35\%:65\%, 65\%:35\%, 100\%:0\%, respectively. Figure 1 shows four types of $\mathrm{CTM}_{i} \mathrm{G}_{r}$ specimens with different RMA contents.

A central composite design was employed to consider the influences of the cement content (C) and the degree of compaction (DC) for a given mixture of $\mathrm{CTM}_{i} \mathrm{G}_{r}$ [11]. Such a factorial design is constructed by considering centre points and star points, which is given in Table 1. It is recommended to use five specimens at the central point $\left(\mathrm{C}_{0} \mathrm{D}_{0}\right)$ and one at each other point.

Based on previous researches, the cement content chosen for cement treated aggregate materials varied from 2.5 to $5.5 \%$. The degree of compaction ranges from 97 to $105 \%$ referred to the standard proctor compaction [4, 12]. Therefore, the mixture in the central point was designed with a cement content of $4 \%$ and a degree of compaction of $101 \%$. The star 

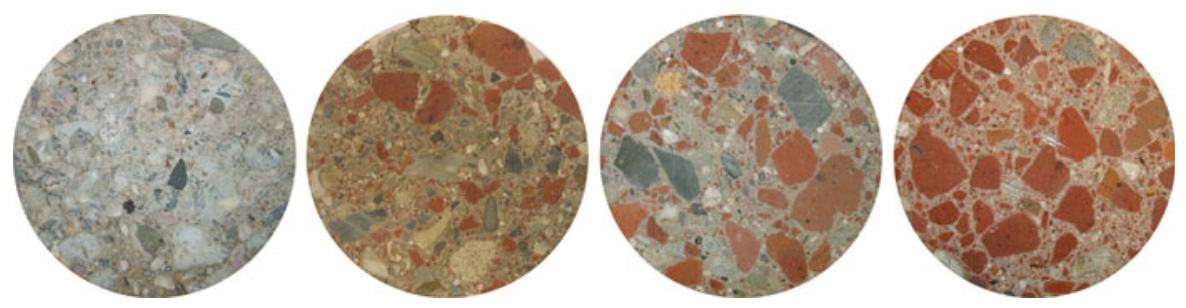

Fig. 1 Cross section of $\mathrm{CTM}_{i} \mathrm{G}_{r}$ specimens (RMA content increases from left to right)

Table 1 Design for two factors at five levels in nine runs

\begin{tabular}{lll}
\hline Items & \multicolumn{2}{c}{ Two variables and their application levels } \\
\cline { 2 - 3 } & $\mathrm{C}$ & $\mathrm{DC}$ \\
\hline $\mathrm{C}_{-\alpha} \mathrm{D}_{0}$ & $-\alpha$ & 0 \\
$\mathrm{C}_{+\alpha} \mathrm{D}_{0}$ & $+\alpha$ & 0 \\
$\mathrm{C}_{0} \mathrm{D}_{-\alpha}$ & 0 & $-\alpha$ \\
$\mathrm{C}_{0} \mathrm{D}_{+\alpha}$ & 0 & $+\alpha$ \\
$\mathrm{C}_{0} \mathrm{D}_{0}$ & 0 & 0 \\
$\mathrm{C}_{-1} \mathrm{D}_{-1}$ & -1 & -1 \\
$\mathrm{C}_{+1} \mathrm{D}_{-1}$ & +1 & -1 \\
$\mathrm{C}_{-1} \mathrm{D}_{+1}$ & -1 & +1 \\
$\mathrm{C}_{+1} \mathrm{D}_{+1}$ & +1 & +1 \\
\hline
\end{tabular}

Note $\mathrm{C}$ means the cement content; DC means the degree of compaction. $+\alpha, 1,0,-1$ and $-\alpha$ present the application levels

points were selected by means of the rotatable composite design method. This is shown in Fig. 2. Equations 4 and 5 establish the relationship between these points.

$$
\begin{aligned}
& \sqrt{2}\left(C_{+1}-C_{0}\right)=\frac{1}{2}\left(C_{\alpha}-C_{-\alpha}\right) \\
& \sqrt{2}\left(D C_{+1}-D C_{0}\right)=\frac{1}{2}\left(D C_{\alpha}-D C_{-\alpha}\right)
\end{aligned}
$$

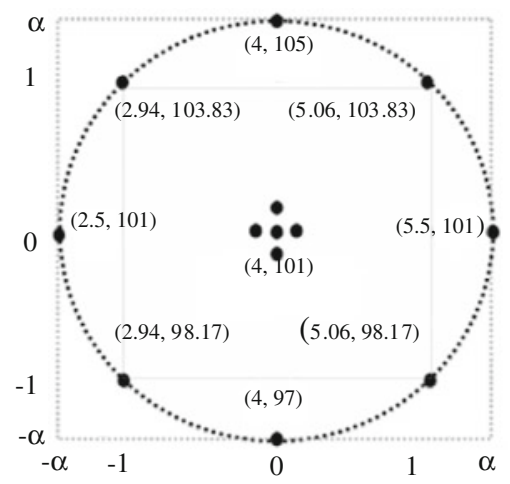

Fig. 2 Central composite design for cement content and degree of compaction

\section{Specimen preparation}

\subsection{Materials}

Two different recycled aggregates, which were collected at two Dutch companies, were used in this study. One is recycled crushed concrete aggregates (RCA) and the other is recycled crushed masonry aggregates (RMA). Both recycled aggregates were divided into six fractions: 31.5-22.4, 22.4-16.0, $16.0-8.0,8.0-5.6,5.6-2.0,<2.0 \mathrm{~mm}$. The physical properties of the different fractions are determined in accordance with the European Standard EN 1097-6, Annex $\mathrm{C}$ and are listed in Table 2. In addition to the recycled aggregates, EN 42.5 Portland cement and tap water were used to prepare the test specimens.

The target gradation for the mix granulates was designed by Eq. 6 . Compared to the Fuller's curve $(n=0.45)$, the target curve has less fines in the mixture. The reason why this gradation is chosen is that RCA does not contain too much fines in practice. In order to be able to reuse as much as crushed concrete aggregates, the target curve was selected for practical reasons.

$P=(100-F) \frac{d^{n}-0.063^{n}}{D^{n}-0.063^{n}}+F$

where, $P$ is the percentage passing sieve size $d, D$ is the maximum particle size ( $31.5 \mathrm{~mm}$ in this study), $F$ is the fines content $(F=2.24$, close to the fines content $(<0.063 \mathrm{~mm})$ in crushed concrete aggregates), $n$ is the parameter describing the shape of the grading curve ( $n=0.45$ in this study).

\subsection{Optimum moisture content by One-Point- Proctor compaction}

In accordance with Annex $\mathrm{B}$ of the European Standard EN 13286-2, four types of $\mathrm{CTM}_{i} \mathrm{G}_{r}$ mixtures with cement content of $4 \%$ by mass of total aggregates were compacted in a One-Point-Proctor 
Table 2 Physical properties of crushed masonry and crushed concrete

\begin{tabular}{lllllr}
\hline Test items & \multicolumn{2}{l}{ Fractions $(\mathrm{mm})$} & & \\
\cline { 2 - 6 } & $31.5-22.4$ & $22.4-16.0$ & $16.0-8.0$ & $8.0-5.6$ & $5.6-2.0$ \\
\hline RMA & & & & $2.0-0.063$ \\
Apparent density $\left(\mathrm{g} / \mathrm{cm}^{3}\right)$ & 2.299 & 2.299 & 2.369 & 2.418 & 2.458 \\
Particle density $\left(\mathrm{g} / \mathrm{cm}^{3}\right)$ & 1.934 & 1.931 & 1.954 & 1.976 & 1.920 \\
Water absorption in $48 \mathrm{~h}(\%)$ & 8.19 & 8.27 & 8.98 & 9.26 & 11.40 \\
RCA & & & & 1.914 \\
Apparent density $\left(\mathrm{g} / \mathrm{cm}^{3}\right)$ & 2.533 & 2.512 & 2.555 & 2.583 & 2.597 \\
Particle density $\left(\mathrm{g} / \mathrm{cm}^{3}\right)$ & 2.354 & 2.313 & 2.322 & 2.336 & 2.311 \\
Water absorption in $48 \mathrm{~h}(\%)$ & 2.99 & 3.41 & 3.91 & 4.10 & 2.596 \\
\hline
\end{tabular}

Table 3 Moisture content and dry density of $\mathrm{CTM}_{i} \mathrm{G}_{r}$ by One-Point-Proctor test

\begin{tabular}{lllc}
\hline $\begin{array}{l}\text { Ratio of } \\
\text { RMA to } \\
\text { RCA }\end{array}$ & $\begin{array}{l}\text { Optimum } \\
\text { moisture content } \\
(\%)\end{array}$ & $\begin{array}{l}\text { Dry } \\
\text { density } \\
\left(\mathrm{g} / \mathrm{cm}^{3}\right)\end{array}$ & $\begin{array}{l}\text { Appearance of } \\
\text { fresh } \mathrm{CTM}_{i} \mathrm{G}_{r}\end{array}$ \\
\hline $100 \%: 0 \%$ & 11.81 & 1.662 & $\begin{array}{c}\text { A little shinny; } \\
\text { no bleeding }\end{array}$ \\
$65 \%: 35 \%$ & 10.94 & 1.754 & \\
$35 \%: 65 \%$ & 10.44 & 1.834 & \\
$0 \%: 100 \%$ & 9.54 & 1.907 & \\
\hline
\end{tabular}

standard test in order to obtain the optimum moisture content. The obtained dry density is then referred to as the $100 \%$ degree of compaction in this study. Table 3 lists the optimum moisture content and the corresponding dry density of $\mathrm{CTM}_{i} \mathrm{G}_{r}$.

It can be seen that with an increase of the RMA content, more water is needed to obtain a good workability. Meanwhile, the dry density of $\mathrm{CTM}_{i} \mathrm{G}_{r}$ at $100 \%$ degree of compaction gradually decreases with the RMA content. This is due to the high water absorption of the recycled RMA and its low density shown in Table 2. Using mathematic relationships, optimum moisture content ( $\left.W_{\text {optimum }}\right)$ and dry density at $100 \%$ degree of compaction $\left(D_{100 \%}\right)$ are related to the RMA content:

$$
\begin{array}{ll}
W_{\text {optimum }}=0.0222 M+9.5724 & \left(R^{2}=0.994\right) \\
D_{100 \%}=-0.0025 M+1.9126 & \left(R^{2}=0.997\right)
\end{array}
$$

where, $W_{\text {optimum }}$ is optimum moisture content of $\mathrm{CTM}_{i} \mathrm{G}_{r}$ by the whole mass of aggregates, $\% ; D_{100 \%}$ is the dry density of $\mathrm{CTM}_{i} \mathrm{G}_{r}$ at $100 \%$ degree of compaction, $\mathrm{g} / \mathrm{cm}^{3} ; M$ is the RMA content by mass of the total aggregates, $\%$.
For a given $\mathrm{CTM}_{i} \mathrm{G}_{r}$ mixture, the optimum moisture content is fixed for the specimen preparation. The required degree of compaction for the specimen varies by adjusting the compaction effect. The following equation may be used to calculate the designed density:

$D_{\text {designed }}=\frac{\mathrm{DC}_{\text {designed }} \times D_{100 \%}}{100}$

where, $\mathrm{DC}_{\text {designed }}$ is the designed degree of compaction, $\% ; D_{\text {designed }}$ is the designed dry density, $\mathrm{g} / \mathrm{cm}^{3}$.

\subsection{Compaction of mixture}

All $\mathrm{CTM}_{i} \mathrm{G}_{r}$ specimens were prepared according to the designed composition and moisture content. In the laboratory $\mathrm{CTM}_{i} \mathrm{G}_{r}$ was firstly mixed by using a laboratory mixer. The fresh mixture with the required mass was then compacted in three layers in a mould of $\varnothing 150 \times 150 \mathrm{~mm}$ by using a vibrating hammer. After 24-h curing in the mould, all specimens were demolded and subjected to a fog-room curing at $20^{\circ} \mathrm{C}$. The curing regime referred to EN 14227-1 Annex C. When the curing time reached 28 days, all specimens were tested.

\subsection{Determination of mechanical properties}

The UCS of the mixtures was measured by using a MTS actuator of $245 \mathrm{kN}$ in the axial displacement control mode. The displacement rate was controlled by three linear variable differential transformers (LVDTs) in the axial direction of the specimen. A friction reduction system was used to obtain uniform radial deformations over the height of the specimen 


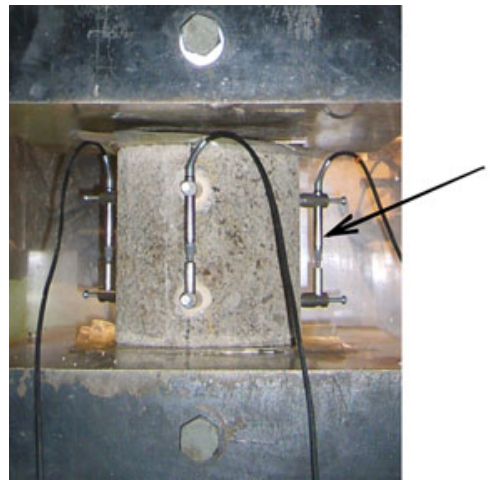

Fig. 3 Compression testing in the laboratory

[13]. The controlled strain rate is $10^{-5} / \mathrm{s}$. The data of the force and the deformation are automatically recorded by a MP3 program. The elastic modulus ( $E_{\text {static }}$ ) of $\mathrm{CTM}_{i} \mathrm{G}_{r}$ is considered as the tangent modulus measured along the linear portion of the stress-strain diagram. Figure 3 shows the experimental compression test.

\section{Statistical analysis}

\subsection{Experimental data}

Table 4 lists all experimental data obtained on basis of the mixture design mentioned above.

\subsection{Predication models}

In previous researches, some relationships have been presented to indicate that the UCS linearly increases with the cement content and has an exponential relation with the dry density. By combining those findings, the following prediction models for the UCS and $E_{\text {static }}$ of $\mathrm{CTM}_{i} \mathrm{G}_{r}$ were obtained:

$$
\begin{aligned}
\mathrm{UCS} & =0.0747 \frac{C}{W_{\text {optimum }}} D_{\text {designed }}^{8} \mathrm{e}^{0.0088 M}(\mathrm{MPa}) \\
\left(R^{2}\right. & =0.946) \\
E_{\text {static }} & =161.3\left(\frac{C}{W_{\text {optimum }}}\right)^{0.71} D_{\text {designed }}^{7.4} \mathrm{e}^{0.0053 M}(\mathrm{MPa}) \\
\left(R^{2}\right. & =0.826)
\end{aligned}
$$

where, $C$ is the cement content by the whole mass of aggregates, $\%$
By using Eqs. 7, 8 and 9, the following two equations are developed:

$$
\begin{aligned}
& \mathrm{UCS}=0.0747 C\left(\frac{D C_{\text {designed }}}{100}\right)^{8} \\
& \frac{(-0.0025 M+1.9126)^{8}}{0.0222 M+9.5724} \mathrm{e}^{0.0088 M}(\mathrm{MPa}) \\
& E_{\text {static }}=161.3 C^{0.71}\left(\frac{\mathrm{DC}_{\text {designed }}}{100}\right)^{7.4} \\
& \frac{(-0.0025 M+1.9126)^{7.4}}{(0.0222 M+9.5724)^{0.71}} \mathrm{e}^{0.0053 M}(\mathrm{MPa})
\end{aligned}
$$

\section{Response surface and contour plot in combination with mixture variables}

5.1 Contour plots of the UCS of $\mathrm{CTM}_{i} \mathrm{G}_{r}$

Figure 4 shows the contour plots of the combined effect of mixture variables on the UCS of $\mathrm{CTM}_{i} \mathrm{G}_{r}$. It can be seen that increasing the degree of compaction can yield an equivalent effect on the UCS of CTM ${ }_{i} \mathrm{G}_{r}$ as increasing the cement content. Moreover, it is quite clear that it is more economic and efficient to achieve a good strength by a good compaction rather than by increasing the cement content. These results are also in agreement with previous findings about the influence of cement content and dry density on cement treated materials $[3,4,14]$. In practice, if the degree of compaction is controlled in the range of 98 and $102 \%$ and the cement content is between 3.0 and $5.0 \%$ in the dashed-line square area, the UCS of $\mathrm{CTM}_{i} \mathrm{G}_{r}$ can be obtained between 2.0 and 8.0 MPa. This strongly depends on the RMA content. In previous researches, the UCS of cement treated natural aggregates mainly distributes between 2.0 and $12 \mathrm{MPa}[3-5,12]$. This means that $\mathrm{CTM}_{i} \mathrm{G}_{r}$ has a good mechanical property as a road base material.

This study also indicates that the RMA content is another factor that influences the mechanical performance of $\mathrm{CTM}_{i} \mathrm{G}_{r}$. If there is a $35 \%$ decrease of the RMA content in $\mathrm{CTM}_{i} \mathrm{G}_{r}$, the UCS may increase with a factor of about 1.5 times. This effect is equivalent to an increase of the degree of compaction of about $3 \%$ or an increase of the cement content of about $1.5 \%$.

In fact, the RMA content in the recycled demolition waste is varying. If designing the required performance of $\mathrm{CTM}_{i} \mathrm{G}_{r}$, this variation in the RMA content in the mixture should be taken into account. 
Table 4 Mechanical properties of $\mathrm{CTM}_{i} \mathrm{G}_{r}$ at 28 days

\begin{tabular}{|c|c|c|c|c|c|c|c|c|c|c|}
\hline \multirow[t]{2}{*}{ Items } & \multicolumn{3}{|c|}{ Variables } & \multicolumn{2}{|c|}{ Mechanical properties } & \multicolumn{3}{|c|}{ Variables } & \multicolumn{2}{|c|}{ Mechanical properties } \\
\hline & $M(\%)$ & $D\left(\mathrm{~g} / \mathrm{cm}^{3}\right)$ & $W(\%)$ & $E_{\text {static }}(\mathrm{MPa})$ & UCS (MPa) & $M(\%)$ & $D\left(\mathrm{~g} / \mathrm{cm}^{3}\right)$ & $W(\%)$ & $E_{\text {static }}(\mathrm{MPa})$ & UCS (MPa) \\
\hline $\mathrm{C}_{0} \mathrm{D}_{0^{-1}}$ & 0 & 1.914 & 9.54 & 13429 & 6.08 & 65 & 1.782 & 10.94 & 7737 & 4.58 \\
\hline $\mathrm{C}_{0} \mathrm{D}_{0}-2$ & & 1.909 & & 9685 & 5.39 & & 1.775 & & 8057 & 4.49 \\
\hline $\mathrm{C}_{0} \mathrm{D}_{0}-3$ & & 1.921 & & 12414 & 6.10 & & 1.773 & & 6373 & 4.51 \\
\hline $\mathrm{C}_{0} \mathrm{D}_{0}-4$ & & 1.890 & & 9797 & 5.25 & & 1.771 & & 8274 & 4.43 \\
\hline $\mathrm{C}_{0} \mathrm{D}_{0}-5$ & & 1.917 & & 9797 & 5.15 & & 1.765 & & 8042 & 4.11 \\
\hline $\mathrm{C}_{-\alpha} \mathrm{D}_{0}$ & & 1.901 & & 8173 & 3.84 & & 1.760 & & 4929 & 2.88 \\
\hline $\mathrm{C}_{+\alpha} \mathrm{D}_{0}$ & & 1.937 & & 14733 & 8.72 & & 1.796 & & 10098 & 7.10 \\
\hline $\mathrm{C}_{0} \mathrm{D}_{-\alpha}$ & & 1.793 & & 7998 & 4.04 & & 1.688 & & 3846 & 2.87 \\
\hline $\mathrm{C}_{0} \mathrm{D}_{+\alpha}$ & & 1.975 & & 12125 & 7.18 & & 1.841 & & 9253 & 6.96 \\
\hline $\mathrm{C}_{-1} \mathrm{D}_{-1}$ & & 1.864 & & 8852 & 3.63 & & 1.710 & & 2887 & 2.16 \\
\hline $\mathrm{C}_{-1} \mathrm{D}_{+1}$ & & 1.931 & & 9946 & 4.76 & & 1.804 & & 4030 & 3.75 \\
\hline $\mathrm{C}_{+1} \mathrm{D}_{-1}$ & & 1.863 & & 7571 & 5.34 & & 1.735 & & 9584 & 4.56 \\
\hline $\mathrm{C}_{+1} \mathrm{D}_{+1}$ & & 1.980 & & 16138 & 10.0 & & 1.839 & & 11347 & 6.93 \\
\hline $\mathrm{C}_{0} \mathrm{D}_{0}-1$ & 35 & 1.865 & 10.44 & 9434 & 5.89 & 100 & 1.682 & 11.81 & 4232 & 4.08 \\
\hline $\mathrm{C}_{0} \mathrm{D}_{0}-2$ & & 1.869 & & 10591 & 5.40 & & 1.679 & & 6715 & 4.05 \\
\hline $\mathrm{C}_{0} \mathrm{D}_{0}-3$ & & 1.868 & & 9890 & 5.98 & & 1.678 & & 6108 & 3.91 \\
\hline $\mathrm{C}_{0} \mathrm{D}_{0^{-4}}$ & & 1.866 & & 11432 & 5.99 & & 1.690 & & 6838 & 4.58 \\
\hline $\mathrm{C}_{0} \mathrm{D}_{0}-5$ & & 1.856 & & 11255 & 5.74 & & 1.667 & & 6041 & 3.92 \\
\hline $\mathrm{C}_{-\alpha} \mathrm{D}_{0}$ & & 1.860 & & 5786 & 3.84 & & 1.678 & & 2496 & 2.17 \\
\hline $\mathrm{C}_{+\alpha} \mathrm{D}_{0}$ & & 1.890 & & 12432 & 8.33 & & 1.700 & & 6642 & 5.54 \\
\hline $\mathrm{C}_{0} \mathrm{D}_{-\alpha}$ & & 1.814 & & 6324 & 4.28 & & 1.636 & & 5616 & 3.23 \\
\hline $\mathrm{C}_{0} \mathrm{D}_{+\alpha}$ & & 1.945 & & 14613 & 7.59 & & 1.752 & & 9284 & 6.07 \\
\hline $\mathrm{C}_{-1} \mathrm{D}_{-1}$ & & 1.825 & & 4680 & 2.73 & & 1.640 & & 5533 & 2.35 \\
\hline $\mathrm{C}_{-1} \mathrm{D}_{+1}$ & & 1.901 & & 9469 & 5.44 & & 1.718 & & 6005 & 3.81 \\
\hline $\mathrm{C}_{+1} \mathrm{D}_{-1}$ & & 1.837 & & 10532 & 6.12 & & 1.660 & & 8874 & 4.84 \\
\hline $\mathrm{C}_{+1} \mathrm{D}_{+1}$ & & 1.927 & & 14740 & 9.02 & & 1.746 & & 10163 & 7.34 \\
\hline
\end{tabular}

$M$ RMA, $D$ dry density, $W$ water, $E_{\text {static }}$ static modulus, $U C S$ compressive strength

5.2 Contour plots of the elastic modulus of $\mathrm{CTM}_{i} \mathrm{G}_{r}$

Figure 5 shows the contour plots of the combined effect of the cement content, the degree of compaction and the ratio of RMA to RCA on the $E_{\text {static }}$ of $\mathrm{CTM}_{i} \mathrm{G}_{r}$. It can be seen that the cement content, the degree of compaction and the RMA content have a similar effect on the $E_{\text {static }}$ of $\mathrm{CTM}_{i} \mathrm{G}_{r}$ as they had on the UCS. The gray region of Fig. 5 indicates that in the practical ranges for both cement content and degree of compaction, the $E_{\text {static }}$ value of $\mathrm{CTM}_{i} \mathrm{G}_{r}$ varies from 4000 to $13000 \mathrm{MPa}$.

It is known that on basis of meso-mechanics material models, the elastic modulus of cement based material is controlled by the nature of the material structure. The cement content governs the bonding strength between aggregates and the matrix's strength. The degree of compaction strongly influences the aggregate skeleton that affects the deformation under loading. As shown in Fig. 5, the aggregate type is a factor that influences the skeleton deformation. In practice, the elastic modulus of RMA is from 5 to $18 \mathrm{GPa}$. The elastic modulus of RCA varies from 30 to 60 $\mathrm{GPa}$, which is determined by the recycled resource [15]. Due to different elastic modulus of the individual aggregates of RMA and RCA, the ratio of RMA to RCA also determines the deformation characteristics of $\mathrm{CTM}_{i} \mathrm{G}_{r}$. 


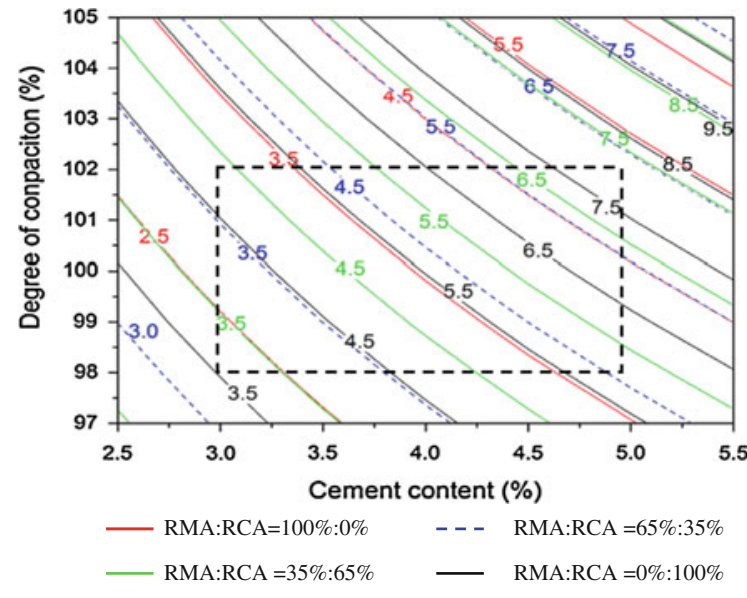

Fig. 4 Contour plots of the combined effect of cement content, degree of compaction and RMA content on the UCS of $\mathrm{CTM}_{i} \mathrm{G}_{r}$

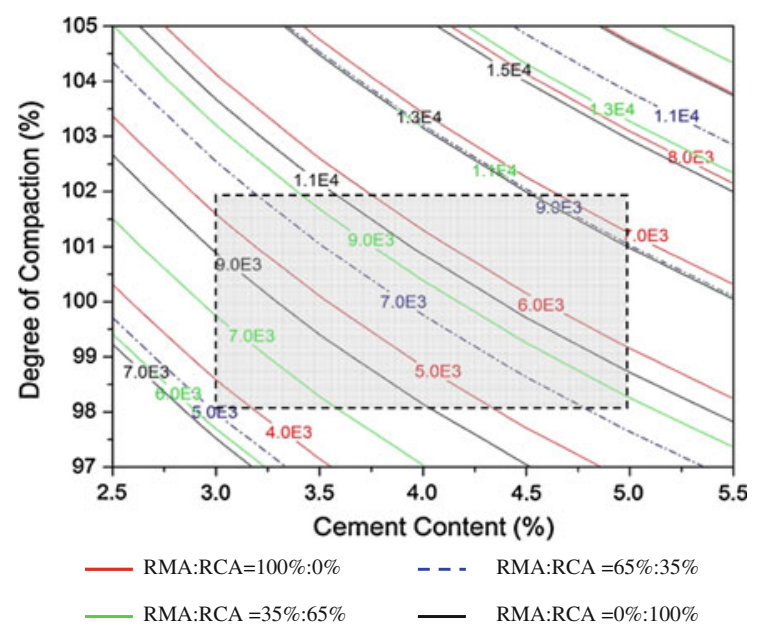

Fig. 5 Contour plots of the combined effect of cement content, degree of compaction and RMA content on the elastic modulus of $\mathrm{CTM}_{i} \mathrm{G}_{r}$

\subsection{Response surface and contour plots of the ratio of UCS to $E$}

Figure 6 shows the response surface and contour plots of the combined effect of the degree of compaction and the cement content on the ratio of UCS to $E$. When increasing the degree of compaction from 97 to $105 \%$, the ratio of UCS to $E$ only increases with about 0.03 . However, increasing the cement content from 2.5 to $5.5 \%$ causes an increase of 0.14 of the ratio of UCS to $E$. The contour lines are nearly vertical, which means that the influence of the degree of compaction on the ratio of UCS to E is rather smaller compared to the influence of the cement content.

Considering the RMA content as a factorial in the mixture, Fig. 7 shows the response surface and contour plots of the combined effect of the cement content and the RMA content on the ratio of UCS to $E$. It is found that the cement content and the RMA content play an equally important effect on the ratio of UCS to $E$. That is, to obtain a high value of the ratio of UCS to $E$, it is needed to increase the RMA content and the cement content.

\subsection{Contour plots of UCS and ratio of UCS to $E$}

Figure 8 shows the contour plots of UCS and ratio of UCS to $E$. It indicates that for a given demolition waste, a required strength or a required ratio of UCS to $E$ can be obtained by adjusting the cement content or the degree of compaction. However, the degree of compaction hardly adjusts the ratio of UCS to $E$. It certainly causes the increase of the flexural rigidity and the strength of the CTB layer. Therefore comprehensive consideration for the mixture optimization should be given to the influence of all mixture variables on the UCS and the ratio of UCS to $E$.

\section{Conclusions and recommendations}

This study employs the response surface technique to investigate the influence of mixture variables on the mechanical properties of cement treated mix granulates with recycled masonry and concrete $\left(\mathrm{CTM}_{i} \mathrm{G}_{r}\right)$. Some main findings are as follows:

(1) Decreasing the masonry content as well as increasing the cement content and the degree of compaction can enhance the unconfined compressive strength and the elastic modulus of $\mathrm{CTM}_{i} \mathrm{G}_{r}$.

(2) The cement content and the RMA content play an equally important role for influencing the ratio of UCS to $E$. Obtaining a high ratio value, one has to adjust the masonry content and the cement content.

(3) Increasing the degree of compaction is an economical method to enhance the strength, but it is not an efficient method to enhance the 
Fig. 6 a Response surface and $\mathbf{b}$ contour plots of the combined effect of degree of compaction and cement content on the ratio of UCS to $E(\mathrm{RMA}=65 \%)$

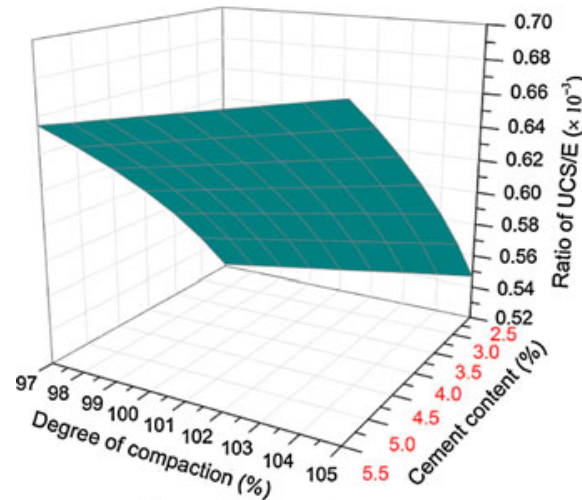

(a) Response surface

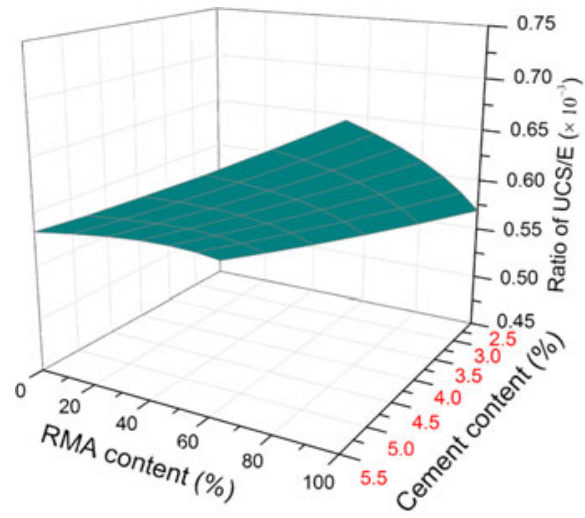

(a) Response surface

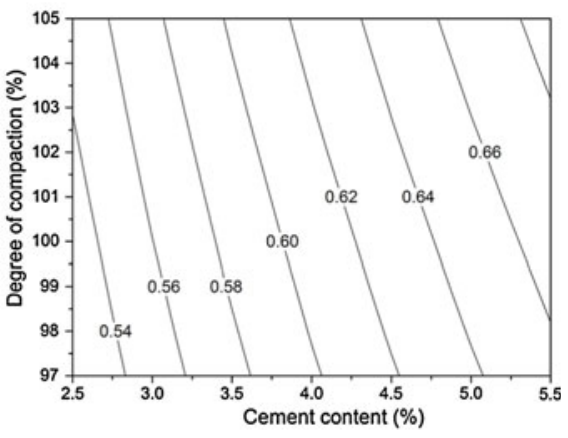

(b) Contour plots
Fig. 7 Response surface and contour plots of the combined effect of RMA content and cement content on the ratio of UCS and $E\left(\times 10^{-3}\right)(\mathrm{DC}=100 \%)$

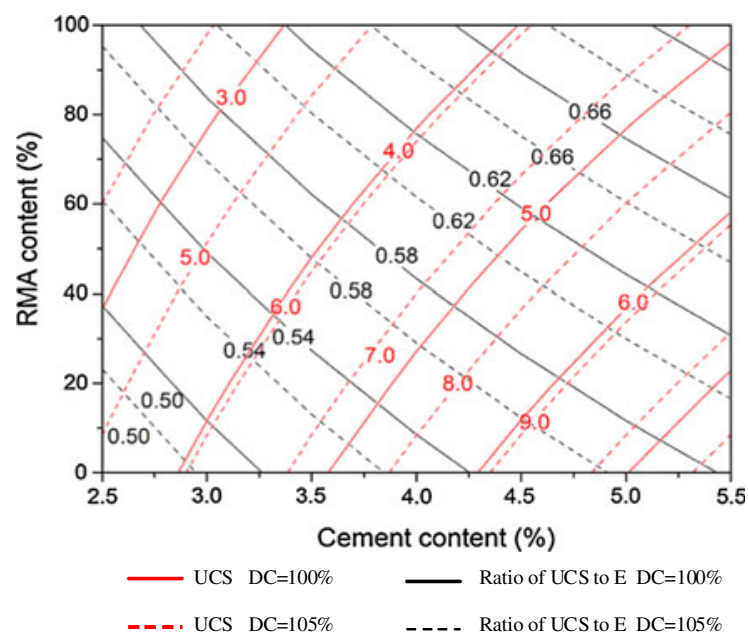

Fig. 8 Contour plots of the combined effect of RMA content, cement content and degree of compaction on the UCS and the ratio of UCS to $E\left(\times 10^{-3}\right)$ admissible elastic strain and improve the flexural rigidity of the CTB layer. The higher this ratio and the better the structural behavior of the $\mathrm{CTM}_{i} \mathrm{G}_{r}$ base layer.

(4) Optimizing the mixture composition of $\mathrm{CTM}_{i} \mathrm{G}_{r}$ should not only consider its material properties, but also the stresses, strain and deformation to which the material is used pavement layer.

It is recommended that in practice the mixture optimization of cement treated demolition waste also needs to compromise the influence of other factors on the mechanical properties and other structural properties. Other factors include the presaturation treatment, the gradation and the granulometry of the aggregate, et al. Meanwhile, this paper mainly focuses on the optimization of mechanical properties in relation to mixture variables, while the shrinkage behavior of $\mathrm{CTM}_{i} \mathrm{G}_{r}$ is not indicated yet. As 
following up this research topic, the shrinkage properties of $\mathrm{CTM}_{i} \mathrm{G}_{r}$, the development of crack pattern in pavements with $\mathrm{CTM}_{i} \mathrm{G}_{r}$ and the structural design of pavements with $\mathrm{CTM}_{i} \mathrm{G}_{r}$ need to be further investigated.

Acknowledgments This work is partially supported by the Chinese Scholarship Council. The authors would like to thank Mr. M.R. Poot, Mr. J.W. Bientjes and Mr. D.C. Doedens (laboratory staff in Road and Railway Engineering, Delft University of Technology) for their assistance during this research.

Open Access This article is distributed under the terms of the Creative Commons Attribution Noncommercial License which permits any noncommercial use, distribution, and reproduction in any medium, provided the original author(s) and source are credited.

\section{References}

1. Cementitious Stabilizers in Road Construction. TRH 13, National Institute for Transport and Road Research, Committee of State Road Authorities, Pretoria, South Africa, 1986

2. Lim S, Zollinger DG (2003) Estimation of the compressive strength and modulus of elasticity of cement-treated aggregate base materials. Transp Res Rec 1837:30-38

3. Terrel RL, Epps JA, Barenberg EJ, Mitchell JK, Thompson MR (1979) Soil stabilization in pavement structures, a user's manual-volume 1: pavement design and construction considerations. FHWA-IP-80-2, Federal Highway Administration, Department of Transportation, Washington DC

4. Williams RIT (1986) Cement-treated pavements: materials, design, and construction. Elsevier Applied Science
Publishers; Sole distributor in the USA and Canada, Elsevier Science Pub. Co., London; New York, USA

5. Terrel RL, Epps JA, Barenberg EJ, Mitchell JK, Thompson MR (1979) Soil stabilization in pavement structures, a user's manual-volume 2: mixture design considerations. FHWA-IP-80-2, Federal Highway Administration, Department of Transportation, Washington DC

6. Babic B (1987) Relationship between mechanical properties of cement stabilized materials. Mater Struct 20(6): 455-460

7. Cai YQ, Cao ZG, Sun HL, Xu CJ (2009) Dynamic response of pavements on poroelastic half-space soil medium to a moving traffic load. Comput Geotech 36(1-2):52-60

8. Kolias S, Williams RIT (1984) Estimation of the modulus of elasticity of cement stabilized materials. Geotech Test J $7(1): 26-35$

9. Xuan DX, Houben LJM, Molenaar AAA, Shui ZH (2010) Cement treated recycled demolition waste as a road base material. J Wuhan Univ Technol Mater Sci Ed 25(4): 696-699

10. Hendriks CF, Janssen GMT (2001) Reuse of construction and demolition waste in the Netherlands for road constructions. Heron 46(2):109-117

11. Robinson GK (2000) Practical strategies for experimenting. Wiley, Chichester

12. Xuan D (2009) Literature review of research project: structural properties of cement treated materials. Report 7-09-217-1, Section Road and Railway Engineering, Delft

13. Erkens SMJG (2002) Asphalt concrete response (ACRe). Delft University of Technology, Delft

14. Molenaar AAA (1998) Road materials-part II: soil stabilization. Lecture Notes CTvb 4850, Delft University of Technology, the Netherlands

15. Hansen TC (1992) Recycling of demolished concrete and masonry: report of technical committee 37-DRC, demolition and reuse of concrete. E \& FN Spon, London 